\title{
The effects of growth hormone injection on children's physical, psychological, and school adjustment factors: comparison by duration.
}

\author{
Hee Yeong Woo* \\ Department of Nursing, Sahmyook Health University, 82 Manguro, Dongdaemun-gu, Seoul, Republic of Korea
}

\begin{abstract}
This study is a descriptive-comparative study to investigate the effects of growth hormone injection on Korean children's physical, psychological and school adjustment factors. This study was conducted on 200 school-age children, and they were divided into two groups: 84 children with the growth hormone treatment duration of below one year and 116 children with the treatment duration of more than 1 year. In terms of the physical factors, there were significant differences in height $(t=-8.91, p=0.001)$ and body weight $(t=-5.45, p=0.001)$. In psychological factors, there were statistically significant differences in body image $(t=4.76, p=0.001)$, optimism $(t=-2.32, p=0.021)$, psychological well-being $(t=-2.37, p=0.019)$, selfesteem $(t=-3.32, p=0.001)$, daily hassles $(t=3.12, p=0.002)$, and school adjustment $(t=-2.24, p=0.027)$. This study has its significance as a fundamental study to develop nursing interventions to promote desirable social and emotional development of children with short stature by comparing the psychological changes of children who are receiving growth hormone treatment.
\end{abstract}

Keywords: Body image, Growth hormone, Optimism, Psychological well-being, Self-esteem.

Accepted on December 6, 2018

\section{Introduction}

There is still room for controversy over whether growth hormone should be actively administered to children with short stature, but many studies have reported positive effects of growth hormone [1]. Particularly in Korea, interest in short stature is increasing with socially increasing interest in appearance [2]. Children with short stature experience various emotional and social relational problems, and become more sensitive to their appearance in the school-age where selfidentity is formed. Negative body image and low self-esteem due to short stature cause confusion of identity [3]. In addition, difficulties in interpersonal relations arise when self-efficacy, a belief expecting a successful outcome in one's work, is low or if there is a lack of optimism, a universal expectation hoping good things will happen rather than bad things. These emotional and social relational problems play a key role in children's school adjustment [4]. In addition, a study on children with short stature [5] reported that children who receive growth hormone have a higher psychological wellbeing than children who do not receive growth hormone. Thus, active interest is needed such as early detection of short stature and growth hormone treatment. However, domestic previous studies on children with short stature are limited, and there are only few foreign studies. This study aimed to provide fundamental data for development of nursing interventions to promote desirable social and emotional development of children with short stature by comparing the psychological changes of children who were receiving growth hormone treatment.

\section{Materials and Methods}

This study is a descriptive-comparative study using a selfreport survey method to confirm the effects of growth hormone injection on children's physical, psychological and school adjustment factors. The subjects of this study were 200 schoolage children who were selected through a growth clinic at a general hospital. The subjects were divided into two groups: 84 children with the growth hormone treatment duration of below 1 year and 116 children with the treatment duration of more than 1 year.

Body image, self-efficacy, optimism, psychological well-being, self-esteem, daily hassles and school adjustment were measured by using the body image [6], self-efficacy scale [7], optimism scale [8], psychological well-being scale [9], Coppersmiths self-esteem inventory, CSEI [10], daily Hassles scale for children [11], and school adjustment scale [12]. The general characteristics were summarized with real number and percentage. The homogeneity of the two groups was analysed by $\chi^{2}$ tests, and the two groups were compared by independent t-tests. Data analysis was performed using SPSS Statistics for Windows version 20.0 (IBM Corp., Armonk, USA). The significant level was set at $\mathrm{p}<0.05$.

\section{Results}

The results of this study are shown in Table 1. In the comparison between the group with the growth hormone treatment duration of below 1 year and the group with the 
treatment duration of more than 1 year, as for the physical factors, there were significant differences in height $(\mathrm{t}=-8.91$, $\mathrm{p}=0.001)$ and body weight $(\mathrm{t}=-5.45, \mathrm{p}=0.001)$. In psychological factors, there were statistically significant differences in body image $(\mathrm{t}=4.76, \mathrm{p}=0.001)$, optimism $(\mathrm{t}=-2.32, \mathrm{p}=0.021)$, psychological well-being $(\mathrm{t}=-2.37, \mathrm{p}=0.019)$, self-esteem $(\mathrm{t}=-3.32, \mathrm{p}=0.001)$, daily hassles $(\mathrm{t}=3.12, \mathrm{p}=0.002)$, and school adjustment $(\mathrm{t}=-2.24, \mathrm{p}=0.027)$.

Table 1. Comparison by growth hormone treatment duration $(n=200)$.

\begin{tabular}{|c|c|c|c|c|}
\hline \multirow[t]{2}{*}{ Variable } & $\begin{array}{lll}\text { Below } & 1 & \text { year } \\
(n=84) & \end{array}$ & $\begin{array}{l}\text { More than } 1 \\
\text { year }(n=116)\end{array}$ & $\mathbf{t}$ & $\mathbf{p}$ \\
\hline & $M \pm S D$ & $M \pm S D$ & & \\
\hline High & $142.50 \pm 0.67$ & $150.96 \pm 0.67$ & -8.91 & 0.001 \\
\hline Weight & $36.78 \pm 0.80$ & $49.95 \pm 0.88$ & -5.45 & 0.001 \\
\hline Body image & $2.83 \pm 0.64$ & $2.38 \pm 0.67$ & 4.67 & 0.001 \\
\hline Self-efficacy & $3.34 \pm 0.55$ & $3.41 \pm 7.55$ & -0.98 & 0.33 \\
\hline Optimism & $3.48 \pm 7.69$ & $3.72 \pm 0.72$ & -2.32 & 0.021 \\
\hline $\begin{array}{l}\text { Psychological well- } \\
\text { being }\end{array}$ & $3.25 \pm 0.76$ & $3.51 \pm 0.41$ & -2.37 & 0.019 \\
\hline Self-esteem & $2.89 \pm 7.49$ & $3.11 \pm 7.41$ & -3.32 & 0.001 \\
\hline Daily Hassles & $1.92 \pm 0.49$ & $1.72 \pm 0.43$ & 3.12 & 0.002 \\
\hline School adjustment & $3.51 \pm 0.51$ & $3.67 \pm 0.50$ & -2.24 & 0.027 \\
\hline
\end{tabular}

\section{Discussion}

In comparison according to the duration of growth hormone treatment, height and body weight were significantly higher in the more-than-one-year treatment group than in the below-oneyear treatment group. This result is similar to that of the previous study on German children with short stature [5], and it has also been confirmed in this study that growth hormone injection in children with short stature produces a significant outcome in the height change. The psychological factor, body image, was positive in the group having received growth hormone more than 1 year, which is consistent with the result of a previous study in Korean children. [3] Moreover, optimism, psychological well-being, and self-esteem were also higher, and daily hassles appeared to be lower in the morethan-one-year treatment group. This is consistent with the result of a previous study that psychological well-being became higher in children with short stature who received growth hormone injection [5]. The result of optimism in this study is similar to that of a previous study that normal-weight children are more optimistic than obese children $[13,14]$. This study result supports the previous study result [3] that short stature at school-age weakens self-esteem. Finally, daily hassles were found to be lower in the more-than-one-year treatment group. This was confirmed to be the same as the result of a study [3] that daily hassles were high in school-age children with short stature. These results suggest that the height growth in children with short stature after growth hormone treatment seemed to make a positive change in the psychological part. Based on these results, it is necessary to find ways to promote desirable social and emotional development of children with short stature.

\section{References}

1. Hintz R, Attie K, Baptista J, Roche A. Effect of growth hormone treatment on adult height of children with idiopathic short stature. N Engl J Med 1999; 340: 502-507.

2. Lee KY. Growth hormone therapy in short stature. J Korean Med Assoc 2008; 51: 849-855.

3. Kim MY. Comparison of body image, self-esteem and behavior problems between

4. children of short and normal stature. Child Health Nurs Res 2010; 16: 41-48.

5. Stabler B, Siegel P, Clopper R, Stoppani C, Compton P, Underwood L. Behavior change after growth hormone treatment of children with short stature. J Pediatr 1998; 133: 366-373.

6. Bullinger M, Kołtowska-Haggstrom M, Sandberg D, Chaplin J, Wollmann H, Noeker M, Brutt A. Healthrelated quality of life of children and adolescents with growth hormone deficiency or idiopathic short stature-part 2: available results and future directions. Hormone Res Paediatr 2009; 72: 74-81.

7. Thompson M, Gray J. Development and validation of a new body-image assessment scale. J Personal Assess 1995; 64: 258-269.

8. Smith H, Betz N. Development and validation of a scale of perceived social self-efficacy. J Career Assess 2000; 8: 283-301.

9. $\mathrm{Mu} \mathrm{G}, \mathrm{Hu} \mathrm{Y}$. Validation of the Chinese version of the 12item child and youth resilience measure. Child Youth Serv Rev 2016; 70: 332-339.

10. Clarke A, Friede T, Putz R, Ashdown J, Martin S, Blake A, Stewart-Brown S. Warwick-Edinburgh mental wellbeing scale (WEMWBS): validated for teenage school students in England and Scotland. A mixed methods assessment. BMC Public Health 2011; 11: 487.

11. Johnson B, Redfield D, Miller R, Simpson R. The Coopersmith self-esteem inventory: a construct validation study. Edu Psychol Measur 1983; 43: 907-913.

12. Seidman E, Allen L, Aber J, Mitchell C, Feinman J, Yoshikawa H, Roper G. Development and validation of adolescent-perceived microsystem scales: Social support, daily hassles, and involvement. Am J Commun Psychol 1995; 23: 355-388.

13. Lee KM, Kim MS. A validation study on the school adjustment scale for middle school students. Korean J School Psychol 2008; 5: 27-40.

14. Braet C, Van Winckel M. Long-term follow-up of a cognitive behavioral treatment program for obese children. Behav Ther 2000; 31: 55-74. 
The effects of growth hormone injection on children's physical, psychological, and school adjustment factors: comparison by duration

\section{"Correspondence to}

Hee Yeong Woo

Department of Nursing
Sahmyook Health University

Seoul

Republic of Korea 